\section{Performance and storage of reagent strips for measuring blood glucose}

Use of reagent strips to monitor blood glucose concentrations in diabetic patients, with or without a glucose meter, is gaining in popularity. Favourable performance of the recently introduced Boehringer BM Test Glycemie 20-800 strips has been reported. ${ }^{1-4}$ We compared Boehringer strips and Dextrostix (Ames) with laboratory measurement of blood glucose. Occasional discrepancies between results determined by test strips and those determined by subsequent laboratory analysis also led us to examine stability of these reagent strips after storage under various conditions.

\section{Methods and results}

Whole blood glucose concentration was measured in 101 patients attending a diabetic clinic by a laboratory glucose-oxidase method (Yellow Springs analyser, Clandon Scientific) and by three experienced operators using Dextrostix and BM strips, with interpolation between colour gradations. Both strips correlated well with laboratory measurement over the range $2 \cdot 2-13.9 \mathrm{mmol} / 1(40-250 \mathrm{mg} / 100 \mathrm{ml})$ with coefficients $(\mathrm{r})$ of 0.87 for Dextrostix and 0.94 for BM strips. This correlation was preserved up to $22.0 \mathrm{mmol} / 1$ $(396 \mathrm{mg} / 100 \mathrm{ml})$ for BM strips. A total of $98 \%$ of results were within one colour gradation for Dextrostix and $100 \%$ for BM strips.

Performance of the strips was examined over 18 weeks' storage of the containers under a variety of conditions, covering most conceivable storage temperatures. The conditions examined were: $(a)$ room temperature, $(b)$ $37^{\circ} \mathrm{C},(c) 4^{\circ} \mathrm{C}$, and $(d)-20^{\circ} \mathrm{C}$ : one sealed and one open container were stored at room temperature, $37^{\circ} \mathrm{C}$, and $4^{\circ} \mathrm{C}$, and a sealed container only was stored at $-20^{\circ} \mathrm{C}$. The tops were removed from the sealed containers and then immediately replaced at weekly intervals for four weeks, and then at eight, 12, and 18 weeks. At one, four, eight, 12, and 18 weeks, strips were used in duplicate to measure blood glucose concentration at high (in the range $10 \cdot 8-13 \cdot 2 \mathrm{mmol} / 1(195-238 \mathrm{mg} / 100 \mathrm{ml})$ for Dextrostix; $16 \cdot 0-19 \cdot 7 \mathrm{mmol} / \mathrm{l}$ (288-355 $\mathrm{mg} / 100 \mathrm{ml}$ ) for $\mathrm{BM}$ strips and low (in the range $1.0-1.6 \mathrm{mmol} / \mathrm{l}$ $(18-29 \mathrm{mg} / 100 \mathrm{ml})$ ) concentrations. Samples were prepared for immediate analysis by adding glucose to heparinised blood. Strips were allowed to equilibrate at room temperature before use. On each occasion results from strips under evaluation were compared with those from strips taken from a previously unopened container.

Storage at room temperature, as recommended by the manufacturers, was associated with least deterioration (see figure). Nevertheless, performance did decline in the case of low glucose values and particularly with Dextrostix. Storage in unsealed containers at room temperature led to more rapid deterioration in all cases. Other modes of storage were associated with pronounced deterioration over a period of eight weeks at both high and low glucose concentrations. Changes occurred most quickly in strips that had

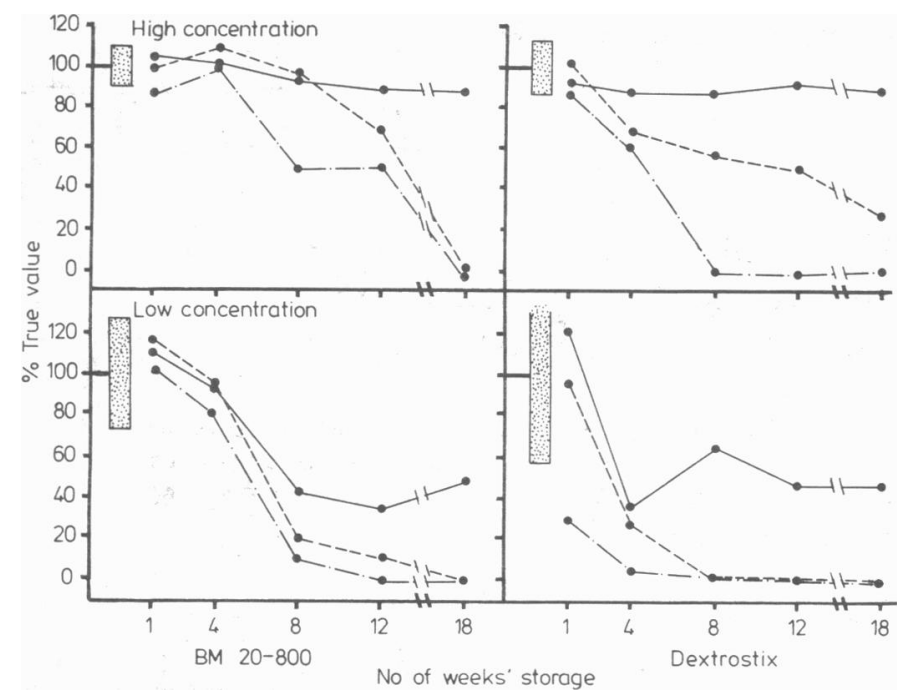

Change in apparent blood glucose concentrations obtained using BM 20-800 and Dextrostix reagent strips at high and low concentrations during 18 weeks' storage at recommended temperature in sealed (- $)$ and unsealed (-containers. Results obtained after storage under most adverse conditions (see text) are also shown (-.-.). Shaded areas represent $95 \%$ confidence limits at the $100 \%$ - that is, true-blood glucose concentrations. been stored in unsealed containers at $37^{\circ} \mathrm{C}$, except for Dextrostix in the high glucose range, which deteriorated more rapidly in the unsealed container at $4^{\circ} \mathrm{C}$.

\section{Comment}

We confirm that trained operators can obtain comparable results between blood glucose concentrations measured by both Dextrostix (up to $13.9 \mathrm{mmol} / 1(250 \mathrm{mg} / 100 \mathrm{ml}$ )) and BM strips (up to $22.0 \mathrm{mmol} / 1$ $(396 \mathrm{mg} / 100 \mathrm{ml})$ ) and formal laboratory measurement. Undoubtedly, incorrect results can be produced by inexperienced personnel. Nevertheless, our results emphasise the importance of correct storage of strips before use. This should be made clear to diabetic patients using strips for home monitoring of blood glucose concentration, with or without a glucose meter. Our findings also suggest that when strips are used to diagnose or monitor hypoglycaemia-for example, in neonatal practice-then storage conditions and shelf-life of strips should be critically assessed. Perhaps hospital chemical pathology departments could usefully offer a "quality assurance" scheme to local users of glucose strips; pilot studies for such a scheme in our own hospitals are now proceeding. As well as ensuring that strips in use give correct blood glucose results, such schemes, in conjunction with training programmes, would in all likelihood lead to an overall improvement in performance of these measurements, as has occurred since the introduction of external quality-control programmes for many tests carried out by laboratories themselves. ${ }^{5}$

${ }^{1}$ Lawson PM, Kesson CM, Ireland JT. Performance of blood-glucose strips. Lancet 1979; ;i:742.

2 Walford S, Clarke P, Paiset R, Hartog M, Allison SP. Home blood-glucose measurements without reflective meter. Lancet 1980;i :653-4.

${ }^{3}$ Earis JE, Greenway MW, Macauley MB. Blood glucose monitoring without a meter. Lancet $1980 ; \mathrm{i}: 823-4$.

4 Ferguson SD, Prosser R. Are reflectance meters necessary for home blood glucose monitoring ? Br Med f 1980;281:912.

5 Whitehead TP, Woodford FP. External quality assessment of clinical laboratories in the United Kingdom. $\mathcal{F}$ Clin Pathol 1981 ;34:947-57.

(Accepted 6 August 1982)

Department of Chemical Pathology, Derbyshire Royal Infirmary, Derby DE1 2QY

G KING, FIMLs, senior chief medical laboratory scientific officer

D STEGGLES, AIMLS, medical laboratory scientific officer

J S HARROP, MSC, MRCPATH, consultant

\section{Appendicitis due to Campylobacter jejuni}

Campylobacter jejuni is now a well-known enteropathogenic bacterium. The number of isolations in Britain almost equals that of Salmonella spp. ${ }^{1}$ Although abdominal pain is a common symptom of campylobacter enteritis, sometimes mimicking appendicitis, $C$ jejuni has not been isolated from the appendix. ${ }^{2}$ In cases where appendicectomy has been performed the appendix has usually been normal or simply fibrosed. ${ }^{3}$ In one case it was inflamed on histological examination but bacteriological culture was not performed. ${ }^{3}$

\section{Case report}

A 16-year-old girl was admitted to hospital with a two-day history of abdominal pain at McBurney's point. Tenderness, guarding, and fever were present. She had had several episodes of diarrhoea in the previous month, but did not have either diarrhoea or bloody stools when admitted to hospital. Appendicitis was diagnosed and a Halsted's appendicectomy performed. Microscopical examination of the inflamed appendix showed an infiltration of lymphocytes, plasmocytes, and polymorphonuclear leucocytes in the mucosa and submucosa. Microbiological examination of the appendix for enteropathogenic bacteria was also carried out, but $C j e j u n i$ was the only notable organism isolated. 


\section{Comment}

In a study of 100 children and young adults with acute appendicitis this is the only occasion on which we found $C$ jejuni in the appendix. The other enteropathogenic organisms found were Salmonella spp (one case) and Yersinia enterocolitica (three cases). Thus appendicitis must be included with other types of localised complications in enteritis due to campylobacter, such as pancreatitis and cholecystitis.

${ }^{1}$ Communicable Disease Surveillance Centre. Campylobacter infections, 1977-80. Br Med f $1981 ; 282: 1484$.

2 Butzler JP, Skirrow MB. Campylobacter enteritis. Clin Gastroenterol $1979 ; 8: 737-65$.

3 Bradshaw MJ, Brown R, Swallow JH, Rycroft JA. Campylobacter enteritis in Chelmsford. Postgrad Med $\mathcal{F}$ 1980;56:80-4.

(Accepted 17 fune 1982)

\section{Children's Hospital, Bordeaux, France}

F MEGRAUD, MD, assistant, department of bacteriology

C TACHOIRE, MD, assistant, department of bacteriology

J LATRILLE, MD, head, department of bacteriology

J M BONDONNY, MD, head, department of paediatric surgery

\section{Leiomyoma of the oesophagus: follow-up of 14 years before operation}

We describe a case of leiomyoma of the oesophagus in which the patient refused operation at the time of initial diagnosis, therefore enabling the condition to be observed for an unusually long time. New techniques of investigation became available during this period. Computed tomography may contribute to the exact preoperative evaluation of the tumour.

\section{Case report}

In 1966 a 19-year-old man was found to have an abnormality on a routine chest $x$-ray film, the upper right mediastinum being widened. Radiography of the oesophagus followed by endoscopy (with a rigid endoscope) suggested a diagnosis of leiomyoma. Typical features seen at endoscopy were sharply defined radiological defects and a bulging mass with intact mucosa. Operation was refused.

In 1973 the patient was referred with minor chest pain and pain between the shoulders. There was no obvious relation to meals. Radiographs of the chest and oesophagus were practically unchanged. He again refused an operation. The findings seemed to support the initial diagnosis.

In 1980 he presented with additional complaints. He experienced dysphagia, mainly with solid food, and occasionally had regurgitations. There was no loss of weight. On chest radiography the widening of the

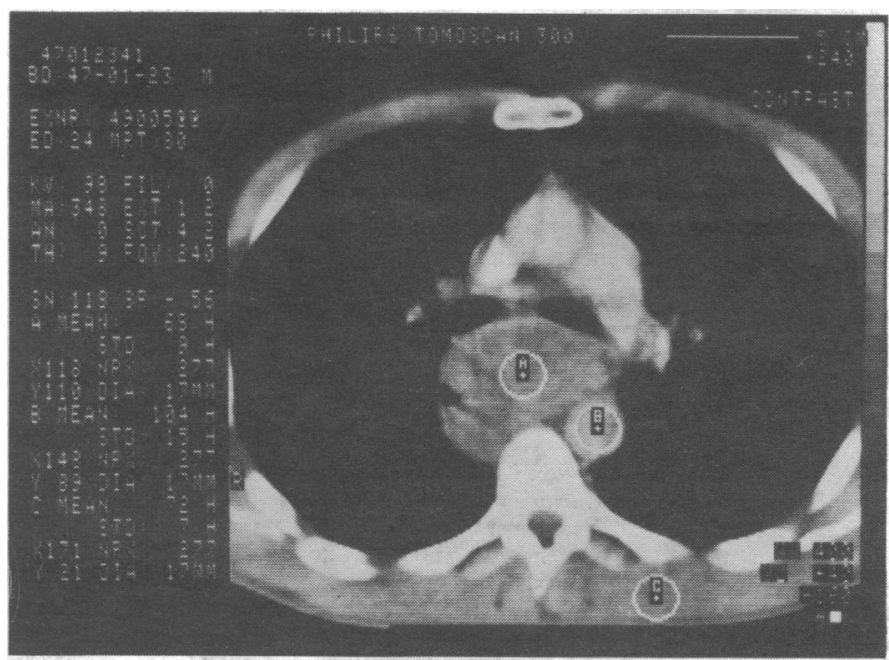

Computed tomogram of area below bifurcation of trachea: the oesophagus (filled with air) is displaced to the right and the main bronchi pushed ventrally by the tumour. mediastinum seemed slightly increased, but this was of doubtful importance. The same applied to changes on the $x$-ray film of the oesophagus. Endoscopy (with a flexible endoscope) again showed an intact mucosa. No biopsy specimen was taken. Computed tomography of the mediastinum (figure) showed a mass with an attenuation coefficient (Hounsfield number ${ }^{1}$ ) compatible with muscle tissue. Its length was estimated at $11 \mathrm{~cm}$, its maximum width $4 \mathrm{~cm}$. Proximally it was located to the right of the oesophageal lumen, more distally it gradually moved to the left.

The patient agreed to an operation and right-sided thoracotomy was performed. After longitudinal incision of the oesophageal muscle the tumour was removed by enucleation. The mucosa was left intact. The specimen had a curved shape and a smooth lobulated surface. Its maximum measurements were $9 \times 8 \times 5 \mathrm{~cm}$, weight $130 \mathrm{~g}$. The consistency was solid, and histology confirmed the diagnosis of leiomyoma. The postoperative period was uneventful.

\section{Comment}

Clinical leiomyoma of the oesophagus is relatively rare. Seremetis et $a l^{2}$ analysed 838 published cases. Postmortem studies have shown an incidence varying from one in 250 to one in 20000 in different series. Scrupulous investigation seems to explain this difference: with histological investigation of the whole oesophagus an incidence of tumours of $5.1 \%$ could be found.

The natural history is intriguing: our patient lived at least 14 years with an impressive tumour, which hardly changed in size. Nevertheless, he gradually developed the typical symptoms. This might be explained by changes in the consistency of the tumour and present an argument for operation, rather than fear of malignant change, which has not been clearly documented. ${ }^{2}$

Leiomyoma may be diagnosed with reasonable certainty by conventional radiography and endoscopy; if the mucosa is normal biopsy is not advisable as it causes complications at operation. Computed tomography, however, has some advantages: it can confirm the type of tissue (with certain limitations ${ }^{4}$ ) by determining the attenuation coefficient; and shows the relation to the aorta, avoiding aortography, as is suggested in certain cases. ${ }^{2}$ Its role is important in establishing the accurate size and spread of the tumour. The decision whether the tumour can be enucleated or whether partial resection will be necessary may then be taken with more certainty.

1 Hounsfield GN. Computerised transverse axial scanning (tomography): part I. Description of system. Br f Radiology 1973;46:1016-21.

2 Seremetis MG, Lyons WS, de Guzman VC, Peabody JW Jr. Leiomyomata

of the esophagus: an analysis of 838 cases. Cancer 1976;38:2166-77.

3 Postlethwait RW, Musser AW, Durham NC. Changes in the esophagus in 1000 autopsy specimens. F Thorac Cardiovasc Surg 1974;68:953-6.

Heitzman E. Computed tomography of the thorax: current perspectives. Am $\mathcal{F}$ Radiology 1981 ;136:3-12.

(Accepted 6 August 1982)

Department of Chest Medicine, de Wever Hospital, Heerlen, Netherlands

B VON PREYSS, MD, medical registrar

F MAESEN, MD, chest physician

\section{Successful treatment of invasive pulmonary aspergillosis complicating influenza $A$}

Invasive pulmonary aspergillosis complicating influenza has been fatal in all four cases reported to date. ${ }^{1-3}$ We report on a patient successfully treated with amphotericin B and flucytosine, followed by econazole when renal function deteriorated.

\section{Case report}

A previously healthy 69-year-old housewife presented with encephalitis and hypoxic respiratory failure nine days after the onset of influenza. She was cyanosed and confused with a tachycardia of 130 beats/min and bilateral coarse crackles at her lung bases. She had increased muscular tone, neck stiffness, and depressed reflexes. Chest radiography showed extensive bilateral patchy shadows in mid and lower zones. Haemoglobin concentration was $12 \mathrm{~g} / \mathrm{dl}$ and white cell count $8.3 \times 10^{9} / 1$ with $16 \%$ lymphocytes. $\mathrm{T}$ cells, measured three weeks later, were depressed to $0.61 \times 10^{\circ} / 1$ but recovered to 